\title{
O Atendimento Pedagógico Domiciliar de alunos que não podem frequentar fisicamente a escola por motivos de saúde: revisão sistemática das investigações realizadas entre 2002 e 2015
}

\author{
Geraldo Eustáquio Moreira* \\ Helma Salla**
}

\section{Resumo}

Esta investigaçáo se relaciona ao atendimento pedagógico domiciliar (APD) no Brasil. Analisou-se as publicaçóes existentes nas bases de dados nacionais sobre o APD, de 2002 a 2015. Especificamente, foram analisados os dados referentes às pesquisas, como o ano de publicação, a modalidade de texto científico, a unidade da federação, o foco das pesquisas e as metodologias utilizadas, observando as categorias e as subcategorias relacionadas ao contexto do APD. Utilizou-se as palavras-chaves dos resumos para a construçáo de uma lista de descritores presentes nos textos relacionados ao APD, mediante a busca de dados sobre as citaçóes e o fator h. A pesquisa bibliográfica com abordagem quantiqualitativa de investigação foi utilizada para a análise dos trabalhos publicados no portal CAPES e no site Google Acadêmico. O uso da frase "atendimento pedagógico domiciliar" foi utilizado como parâmetro e foram selecionadas 277 pesquisas, quando encontraram-se 10 trabalhos relacionados ao APD. Foram utilizados o software Harzing's Publish, o Mendeley, o OringinPro8 e o Word clud art para as análises e, para os resultados mais significativos, foram feitas as nuvens de tags. Os resultados demostraram que existe, no Brasil, poucos pesquisadores preocupados com os contextos e a efetivação do APD; que existe formação inicial e continuada na área do APD, mesmo que de forma pontual, sendo a maioria na regiâo Sul; que o índice h de muitos trabalhos era inexistente ou zero, sendo 2 o maior, o que demonstra uma pesquisa científica ainda pouco significativa na área do APD. Neste sentido, existe uma área de investigação crescente relacionada ao APD, que possibilita o crescimento da formaçáo e informação de uma sociedade preocupada com o esse tipo de atendimento pedagógico.

Palavras-chave: Pedagogia hospitalar; Atendimento Pedagógico Domiciliar; Aluno acamado.

* Professor doutor da Universidade de Brasília, Brasília, Distrito Federal, Brasil.

** Mestre em Ensino de Ciências pela Universidade Estadual de Goiás, Anápolis, Goiás, Brasil. 


\section{The Home Pedagogical Assistance of students who can not physically attend school for health reasons: systematic review of the investigations carried out between 2002 and 2015}

\section{Abstract}

This research is related to home pedagogical service (HPS) in Brazil. The publications in the national databases on HPS, from 2002 to 2015, were analyzed. Specifically, the research data, such as the year of publication, the scientific text modality, the unit of the federation, the focus of the studies were analyzed. Research and the methodologies used, observing the categories and subcategories related to the context of the HPS. The keywords of the abstracts were used to construct a list of descriptors present in the texts related to the HPS, through the search of citation data and the factor $h$. The bibliographic research with quantitative research approach was used to analyze the works published in the CAPES portal and in the Google Academic site. The use of the phrase "home pedagogical assistance" was used as a parameter and 277 researches were selected, when 10 HPS related papers were found. Harzing's Publish, Mendeley, OringinPro8 and Word clud art software were used for the analyzes and, for the most significant results, tag clouds were made. The results showed that there are few researchers in Brazil who are concerned about the contexts and the effectiveness of HPS; That there is initial and continuing training in the area of HPS, even in a timely manner, with the majority in the South region; That the index h of many works was non-existent or zero, being 2 the largest, which shows a scientific research still not very significant in the area of HPS. In this sense, there is a growing area of research related to HPS, which enables the growth of training and information of a society concerned with this type of pedagogical service.

Keywords: Hospital pedagogy; Home Pedagogic Assistance; Bedridden student.

\section{Ideias introdutórias e problematização}

A educação como dever do Estado e da família, e direito de todos, é defendida em todos os níveis e setores (BRASIL, 1996). Prerrogativa resultante de um contexto construído com muitas lutas sociais, todas ligadas direta ou indiretamente a pessoas excluídas das escolas, assim como cientistas e simpatizantes destes movimentos, surgiram também resultados de âmbito global, que fortaleceram a inclusão de todos na escola aos níveis internacional, nacional e regional.

Em 1948, cenário de reconstrução e reconciliação do pós-guerra mundial, com pessoas doentes e muitos mutilados de guerra, a Organização das Naçóes Unidas (ONU) lançou a Declaraçáo Universal dos Direitos do Homem, cujo fundamento está no reconhecimento da dignidade de todas as pessoas e na universalidade e indivisibilidades desses: todos os seres humanos nascem livres e iguais em dignidade e direitos. Entre os direitos preconizados pela Declaração, está o acesso à educação básica. 
$\mathrm{O}$ art. 26, item 1, expressa que "toda pessoa tem direito à educação. A educação deve ser gratuita, pelo menos a correspondente ao ensino elementar fundamental”, porque este é obrigatório, uma vez que "o acesso aos estudos superiores deve estar aberto a todos em plena igualdade, em função do seu mérito" (UNESCO, 1948, s/p).

Vimos, então, que o direito à escola é uma realidade nas leis de acesso à educação, mas ainda não concretizado em todos os setores e níveis. Os alunos impossibilitados de frequentar a escola por motivo de doença não estáo inseridos efetivamente na escola para todos. Portanto, não seria possível afirmar que o direito à educação e à inclusão escolar lhes seja assegurado. Assim, verifica-se que o Atendimento Pedagógico Domiciliar (APD) para alunos impossibilitados de frequentar a escola por motivo de saúde, objeto deste estudo, é uma condição específica assegurada, e reafirmada no artigo 58 , parágrafo $2^{\circ}$, porque esse "atendimento educacional será feito em classes, escolas ou serviços especializados, sempre que, em função das condiçóes específicas dos alunos, não for possível a sua integração nas classes comuns de ensino regula" (BRASIL, 1996, p. 20).

Desde 2002 o Ministério da Educação propôs orientaçóes gerais para o APD, porém não são todas as secretarias de educação municipais, estaduais e distrital que possuem normativas com instruçóes gerais de como aconteceria este atendimento. Existem poucas iniciativas para a efetivação do APD aos alunos impossibilitados de frequentar a escola fisicamente por motivos de saúde.

Cumpre às classes hospitalares e ao atendimento pedagógico
domiciliar elaborar estratégias e orientaçóes para possibilitar o
acompanhamento pedagógico-educacional do processo de desen-
volvimento e construção do conhecimento de crianças, jovens e
adultos matriculados ou não nos sistemas de ensino regular, no
âmbito da educaçáo básica e que encontram-se impossibilitados
de frequentar escola, temporária ou permanentemente e, garantir
a manutençáo do vínculo com as escolas por meio de um currí-
culo flexibilizado e/ou adaptado, favorecendo seu ingresso, retor-
no ou adequada integraçáo ao seu grupo escolar correspondente,
como parte do direito de atençáo integral (BRASIL, 2002, p. 13).

A Pedagogia Hospitalar nasceu em Paris, no ano de 1935, quando Henri Sellier desenvolveu um trabalho pedagógico com crianças tuberculosas, ganhando força em 1939 com a inauguração de um centro de formação de professores para atender em hospitais naquele país (ESTEVES, 2008; XAVIER, 2013). Tornou-se um movimento presente em vários países, principalmente após a Segunda Guerra Mundial, quando os profissionais envolvidos na reabilitação perceberam a necessidade dos feridos hospitalizados de receberem um atendimento integral, que os estimulassem e os reinserissem na sociedade (XAVIER, 2013), mesmo impossibilitados de ir à escola.

Para Zaias e De Paula (2010), a Pedagogia Hospitalar possibilita aos acamados não apenas uma distração, mas o acesso ao conhecimento socialmente construído, desenvolvendo contextos de aprendizagens e de inclusão social, possibilitando ao paciente uma melhor qualidade de vida gerada pelo aumento da autoestima. 
A Pedagogia Hospitalar e o Atendimento Pedagógico Domiciliar (APD) são unidos pelo público alvo e diferenciados pelo local do atendimento. Enquanto a Pedagogia Hospitalar acontece no ambiente de internação, em salas adaptadas ou nos leitos dos pacientes (DE PAULA; ZAIAS; SILVA, 2015), o APD está inserido na Pedagogia Hospitalar e se caracteriza por acontecer no ambiente domiciliar do paciente. Geralmente, o estudante atendido é acometido de uma doença que o impossibilita de frequentar a escola, mas que o possibilita estar no aconchego do lar, com o acompanhamento das equipes médica e escolar (SALLA; SANTOS; RAZUCK, 2015).

$\mathrm{O}$ direito à escola é um fato. Porém, como ficam os alunos que não podem frequentar a escola por motivo de doença? Como está a escola para todos neste contexto? Seria possível afirmar que o direito a educação e a inclusão escolar estão garantidos para o APD? Para responder estes questionamentos delineamos como objetivo geral investigar as normativas para o APD de alunos que não podem frequentar fisicamente a escola por motivos de saúde, por meio de uma revisão sistemática das investigaçóes realizadas entre os anos de 2002 e 2015. De forma restrita, intencionamos fazer essa revisão bibliográfica em bases de dados nacionais nos Trabalhos de Conclusão de Curso (TCC), dissertaçóes e teses e, também, possibilitar o entendimento de alguns aspectos que envolvem as pesquisas relacionadas ao APD, principalmente aqueles que nos fazem perceber que estamos no início da caminhada da efetivação do direito à escola para todos.

Assim, é nosso interesse analisar esses trabalhos e mostrar como são apresentados à comunidade científica e ao público em geral, considerando os descompassos entre o que se fala e o que se vive acerca do APD. Neste sentido, nos inquietamos com a questão: como está a pesquisa relação ao APD no Brasil? Analisamos os dados referentes às pesquisas mencionadas (teses, dissertaçóes e os trabalhos de conclusão de curso), tais como ano de publicação, a modalidade de texto científico, a unidade da federação, o foco das pesquisas e as metodologias utilizadas para a análise dos dados, observando as categorias e as subcategorias relacionadas ao contexto do APD. Fizemos o esquadrinhamento das palavras-chaves nos resumos, construindo uma lista de descritores; procuramos no texto completo a incidência dos descritores dos resumos; buscamos os dados sobre as citaçóes e, ainda, o fator h das pesquisas analisadas.

Este estudo se justifica por entendermos que proporcionar uma escola de qualidade para todos é garantir um direito dos cidadãos, que está assegurado em acordos internacionais geradores de políticas públicas na forma de leis, orientaçóes e normativas, existentes também em nosso País. Mas também é necessária a efetivação do direito à educação aos alunos impossibilitados de frequentar a escola por motivo de saúde. Ao investigarmos o APD, entendemos o contexto existente e como é a oferta desta modalidade de educação, resultando na proposta de açóes que possibilitam contextos nos quais os alunos acamados e/ou com deficiência possam ter efetivado o direito à inclusão escolar. Neste sentido, a contribuição desta pesquisa está relacionada a uma mudança do contexto referente ao APD, o que pode nos possibilitar uma escola efetivamente inclusiva, mesmo para os alunos que não podem frequentar fisicamente a escola. 


\section{Metodologia}

A pesquisa bibliográfica permite buscar informaçóes para responder seus próprios questionamentos nos textos dos outros autores, possibilitando não apenas saber o que está a ser pesquisado na área, mas também uma visão geral dos problemas relacionados ao seu objeto de pesquisa.

Assim, este estudo se caracteriza por sua abordagem quantiqualitativa de investigação. Segundo Vanti (2002), a esse tipo de pesquisa se faz necessária para que possamos ter uma ampla visão dos fatos relativos ao desenvolvimento da ciência. Para o desenvolvimento do estudo, embasamo-nos na cienciometria para realizar as pesquisas sobre as questóes relacionadas ao desenvolvimento da investigação científica na área do APD; retiramos os trabalhos publicados do portal CAPES e do site Google Acadêmico e, também, usamos como ferramenta os softwares Harzing's Publish, Mendeley, OringinPro8 e Word clud art para as análises.

Enquanto para Vanti (2002) a cienciometria é o estudo dos aspectos quantitativos da ciência enquanto uma disciplina ou atividade econômica, ou seja, é um segmento da sociologia da ciência, sendo aplicada ao desenvolvimento de políticas científicas, para Yamakawa e colaboradores (2014) o Mendeley é um gerenciador bibliográfico, que surgiu em 2008, utilizado por pesquisadores para a busca e a organização de trabalhos publicados. Por outro lado, o Harzing's Publish é um programa de software que recupera e analisa citaçóes acadêmicas. Ele usa o Google Acadêmico e Microsoft Academic Search para obter as citaçóes em bruto, em seguida, os analisa e apresenta as suas métricas.

\section{contexto da pesquisa}

Os artigos em análise foram retirados do portal CAPES e do banco de dados do Google Acadêmico. O primeiro é um meio de comunicação e divulgação científica brasileira, bem como uma das linhas de ação da Coordenação de Aperfeiçoamento de Pessoal de Nível Superior (CAPES) que possibilita realizar pesquisas relacionadas às publicaçóes de artigos, trabalhos de conclusão de cursos, dissertaçóes e teses. Contribui não apenas para a divulgação, mas também para a unificação das pesquisas de cientistas brasileiros de todas as áreas. A CAPES foi criada em 1951 e desde 2007 tem como objetivo "[...] assegurar a existência de pessoal especializado em quantidade e qualidade suficientes para atender às necessidades dos empreendimentos públicos e privados que visam ao desenvolvimento do país" (CAPES, 2015).

O outro banco de dados é de domínio público. Segundo o mesmo, "a missão do Google é organizar as informações do mundo e torná-las mundialmente acessíveis e úteis". Para o Google (2016), o banco de dados prima por uma atividade centrada no usuário, tem como produto a informação rápida, universal e de qualidade para possibilitar uma melhor qualidade de vida a todos. Entre seus produtos está a divulgação de artigos e teses, disponibilizadas no Google Acadêmico (BRIN; PAGE, 1998).

Os softwares usados na Cienciometria são importantes meios de obtenção de dados estatísticos que poderão ser analisados pelo pesquisador que, embasado em 
pesquisas e nas observaçóes do contexto existente, propóe uma resposta qualitativa às observaçôes (BITTENCOURT; PAULA, 2012). O Harzing's Publish se mostra uma importante ferramenta para calcular o fator $h$, para que possamos entender a importância da pesquisa realizada, assim como o crescimento de uma área científica. fator $h$ é:

Esclarece-se que, de acordo com Thomaz, Assad e Moreira (2011, p. 91), o

[...] muito utilizado como forma de avaliar o impacto do pesquisador individualmente. Muitos autores consideram-no não somente a forma mais segura de mensurar a qualidade científica do pesquisador, como também uma boa ferramenta de avaliação da regularidade da produção e previsão do desempenho científico futuro, pois combina produtividade com impacto.

O Mendeley, por sua vez, entre outras funçôes, seleciona palavras e expressōes de um texto e ajuda na busca e análise dos textos (YAMAKAWA et al, 2014). Por fim, o Word Tagul Clouds é um programa gratuito, cuja ferramenta auxilia os pesquisadores a trabalharem com os descritores, possibilita a obtenção de dados referentes à incidência de determinada palavra em um texto, formando a nuvem de Tags, construída tendo como base a incidência de palavras em determinado texto ou lista de palavras.

\section{Procedimento de recolha e análise dos dados}

Para coletar os dados, definimos como parâmetros o uso da frase "atendimento pedagógico domiciliar" e o período compreendido ficou entre os anos de $2002 \mathrm{e}$ 2015. Entendemos que esse termo estaria presente nos descritores ou no corpo do texto. A seleção do tempo de investigaçáo se relaciona a um dos descritores para o APD, uma vez que o MEC lançou o documento Classe hospitalar e o atendimento pedagógico domiciliar: estratégias e orientaçôes (BRASIL, 2002).

Realizamos a busca usando o Google Acadêmico e o portal da CAPES, mediante a expressão e o período preestabelecidos. Dos resultados encontrados, foram separados os textos relacionados ao APD, tais como TCC, dissertaçóes e teses. Observamos, primeiramente, os títulos e os resumos. Depois, lemos os corpos dos trabalhos e separamos aqueles que têm como foco de pesquisa o APD.

Em seguida, analisamos os trabalhos selecionados observando os dados referentes às pesquisas como o ano de publicação, a modalidade de texto científico, a unidade da federação, o foco das pesquisas e as metodologias utilizadas para a análise dos dados.

Usamos o programa Word Tagul Clouds para buscarmos as palavras de maior incidência e relevância nos resumos; separamos os dados em tabelas e, usando o mesmo programa, construímos uma nuvem de Tags com os descritores. Empregamos o programa Mendeley para buscar as palavras anteriormente selecionadas. Assim, obtivemos a quantidade de citaçóes e o fator h das publicaçóes usando o software Harzing's Publish. Por fim, realizamos a busca manual das citaçóes no Google Acadêmico. 


\section{Resultados e discussões}

O resultado da busca no site do Google Acadêmico nos revelou 277 documentos, do quais separamos 53 que julgamos pertinentes após a análise do título e o resumo. Quando lemos o corpo das pesquisas selecionadas encontramos 10 trabalhados relacionados ao APD. Os outros textos foram descartados por serem artigos ou pesquisas apenas na área da classe hospitalar, cujo foco não era o APD. No portal da CAPES encontramos dois artigos que já estavam presentes na pesquisa anterior.

Embora o recorte de tempo da nossa amostra seja as publicaçóes compreendidas entre os de 2002 e 2015, encontramos pesquisas a partir do ano de 2008. O Gráfico 1 nos mostra que há poucas produçóes científicas na área do APD, o que pode ser explicado pela falta de informação sobre o direito a este atendimento, assim como a efetivação do mesmo em algumas Unidades da Federação. Esta conjuntura provoca um problema social que desperta o interesse dos estudiosos em pesquisar casos existentes ou a falta dos mesmos, na tentativa de mudar o contexto existente no País.

Gráfico 1: Pesquisa na área do APD

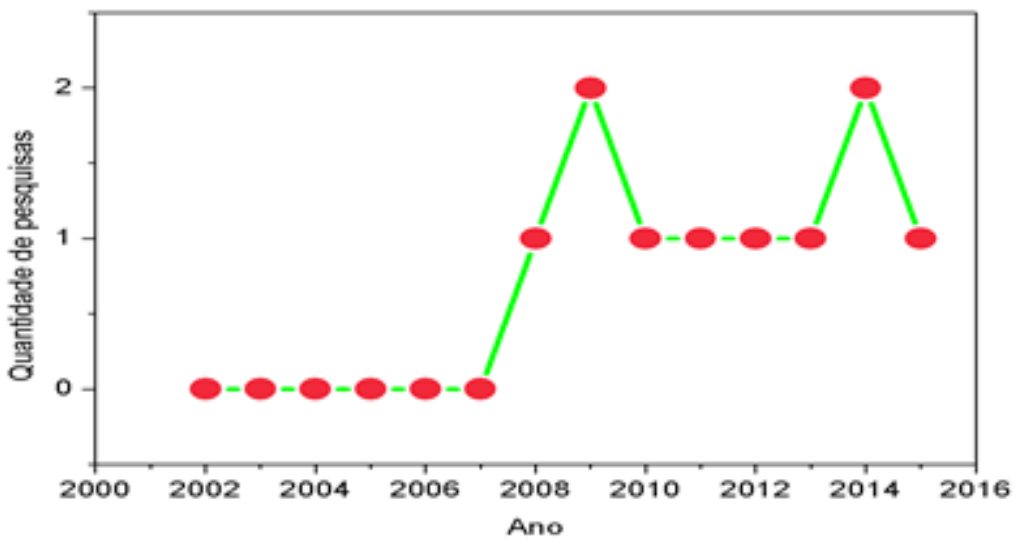

Pelo que ser observa no Gráfico 1, de 2008 a 2010 tivemos um pico nas publicaçôes realizadas, que, posteriormente, foram estagnadas até o ano de 2013, quando tivemos mais algumas publicaçóes até o ano de 2016. Segundo Laplane, Jajbhay e Frederico (2015) é necessário que existam políticas e açôes que de fato garantam o APD, em todas as unidades da federação. Na mesma direção, Peters (2015) defende que o APD seja efetivamente implantado e levado àqueles que necessitam.

Os focos das pesquisas analisadas demostram que existem, no Brasil, pesquisadores preocupados com os contextos e a efetivaçáo do APD, como observamos no Gráfico 2. Podemos inferir, também, que existe um entrelaçamento desses focos na medida em que náo existe uma pesquisa social que não envolva vários aspectos do contexto. 
Gráfico 2: Foco das pesquisas do APD

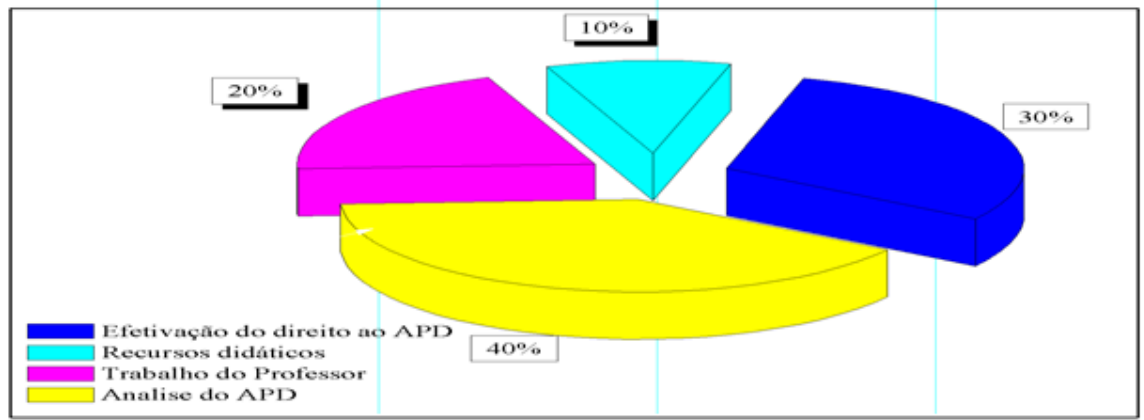

Os trabalhos em que os focos se relacionaram à análise do APD e aos recursos didáticos usados no atendimento, demostram que o pesquisador buscou observar o que está acontecendo para que o trabalho pedagógico seja melhorado ou objetivam mostrar o contexto existente. As pesquisas sobre o trabalho pedagógico demostram a necessidade de investimento em vários aspectos, como a formação de professores e a disponibilidade de recursos pedagógicos.

Para Moreira e Manrique (2014c), uma das formas de corrigir tais distorçóes na formação docente é:

(...) a oferta de formação continuada aos professores, que deve ser oferecida pelas universidades e pelos pares nos contextos educativos, levando-se em consideraçáo as necessidades dos profissionais, objetivando a ruptura com a escola inclusiva estacionária, é uma atitude que pode ajudar na solução do problema (p. 473, tradução nossa).

As pesquisas sobre a efetivação do direito ao APD demostram a fragilidade existente na área, pois é negado em contextos em que há pouca informação da sociedade sobre o tema. E na pesquisa que analisa os documentos sobre o APD, os argumentos, apesar de contrários ao APD, favorecem-no à medida que analisamos seu discurso e percebemos a falta de consistência do mesmo.

Como podemos observar no Gráfico 3, o estudo de caso é predominante nas amostras. Acreditamos que um dos motivos para este fator são as características desta modalidade de análise. De acordo com Minayo (2009), distinguem-se pela observação de um contexto significativo e representativo de forma aprofundada, sendo pesquisados o máximo de aspectos que possam ser abordados, a fim de que os dados sejam compartilhados por outras pessoas em outros contextos e que também possam ser generalizados. 


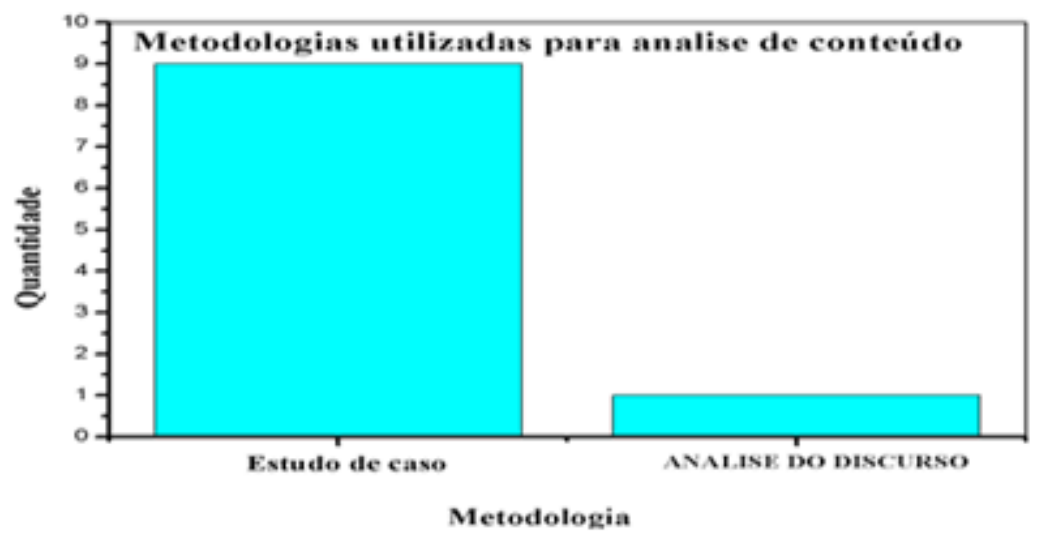

Em relação à análise de conteúdo escolhida por pesquisadores, trata-se de uma metodologia que possibilita a abrangência do tema pesquisado "[...] de se compreender criticamente o sentido manifesto ou oculto das comunicaçóes" (SEVERINO, 2013, p. 121). Para o APD é importante, pois possibilita entender as concepçóes sociais, propiciando ao pesquisador sugerir mudanças sociais significativas, desde que esteja embasado em teorias cujo paradigma tenha a escola como importante para o desenvolvimento pessoal e social.

Em relação às modalidades dos textos científicos, verificamos que já existe uma formação inicial e continuada na área do atendimento pedagógico domiciliar no País, mesmo de forma pontual.

O TCC possibilita ao aluno aprofundar-se nas particularidades de determinada área. Para o desenvolvimento e a efetivação do APD, esta formação inicial do professor se demonstra essencial. Ter essa modalidade de texto acadêmico em nossa amostra nos faz refletir sobre a existência de trabalhos, mesmo que sejam em níveis iniciais de pesquisas.

As dissertaçóes e teses, por sua vez, são elaboradas com estudos mais aprofundados e possuem um caráter inédito, em que o investigador, ao final do curso, demonstra seu conhecimento sobre determinada área, na forma de uma pesquisa científica que aborda diversos aspectos do problema estudado. $\mathrm{Na}$ área do ensino, os Mestrados Profissionais fazem parte da formação continuada dos professores e tem produzido investigaçóes que se assentam na temática do APD.

Observamos que existem publicaçóes destes textos acadêmicos que nos oportunizam verificar a existência de um grupo de pesquisa no País relacionado ao APD, sendo a maioria na região Sul, sobretudo no estado do Paraná, em que há cursos de curta duração, especialização e mestrado profissionalizante na área, previsto dentro da estrutura do plano de desenvolvimento da Pedagogia Hospitalar e Domiciliar, me- 
diante a formação continuada de professores. Estes grupos de pesquisa ajudam no desenvolvimento das políticas públicas na área, mas reforçam a necessidade que eles sejam estendidos a todos os estados brasileiros.

A maioria das pesquisas publicadas é proveniente do estado do Paraná, que possui um APD sistematizado com uma rede de apoio ao aluno e ao professor, inclusive com a formação continuada para os docentes na área do atendimento pedagógico domiciliar.

Conforme o Gráfico 4, o estado do Paraná tem a maior quantidade de pesquisas relacionadas ao APD. Nos outros estados, as pesquisas se relacionam a estudo de casos pontuais ou sobre o direito do APD e a sua inexistência, além de abordar as concepçôes dos professores.

Gráfico 4: Unidades da Federação com maior número de pesquisas

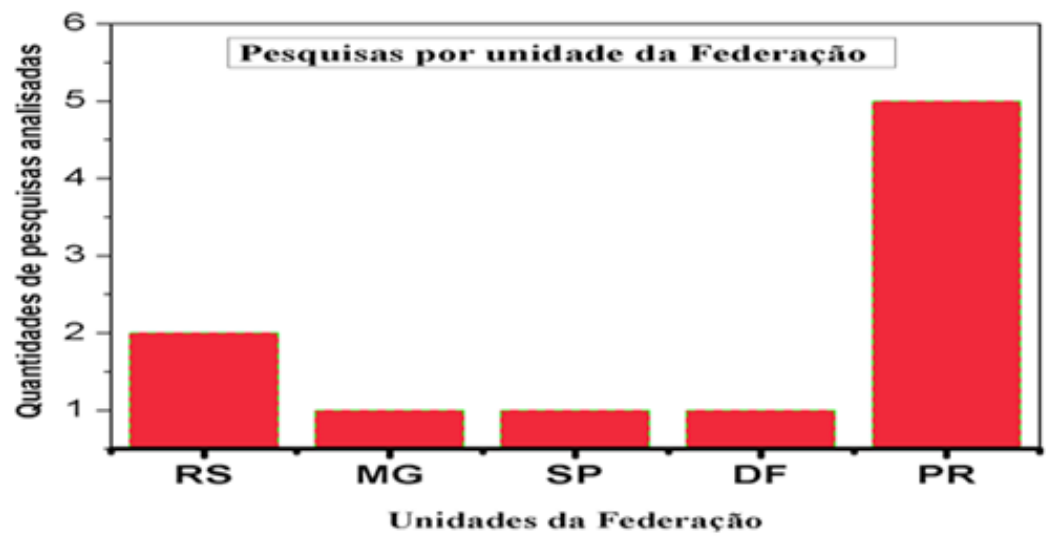

Todos os dados analisados apontam para a necessidade do aumento das pesquisas em todo o país, pois esta é uma possibilidade de mudança do contexto existente, que ainda é tímido quando comparado a outras políticas de atendimento ao estudante com necessidades educativas especiais (NEE).

As contribuiçôes finais da maioria das pesquisas se relacionam às questôes da garantia do direito ao APD e à existência de um trabalho árduo à frente. Pontuam a importância da concepção dos professores, a qualidade e efetivação do atendimento como fator importante, a formação e a informação sobre o tema para os professores.

\section{Resultado das palavras-chaves dos textos do APD}

Na Tabela 1, observa-se que os descritores que se destacaram pela incidência ou pela relevância são: "Educação, Criança, Atendimento, Hospitalar, Escolar, Saúde, Domiciliar, Direito, Aluno, Professor, Adolescente, Pedagógico, Família, Política, Inclusão, Médico, Social”. 
O foco se relaciona ao entendimento dos contextos associados à educação e aos contextos sociais que envolvem os alunos acamados.

Tabela 1: Resultado dos descritores dos resumos

\begin{tabular}{|l|c|}
\hline \multicolumn{1}{|c|}{ Descritor } & Incidência \\
\hline Educaçáo & 33 \\
\hline Criança & 30 \\
\hline Atendimento & 29 \\
\hline Hospitalar & 21 \\
\hline Escolar & 18 \\
\hline Saúde & 17 \\
\hline Domiciliar & 15 \\
\hline Direito & 14 \\
\hline Aluno & 14 \\
\hline Professor & 13 \\
\hline Adolescente & 11 \\
\hline Pedagógico & 11 \\
\hline Família & 9 \\
\hline Política & 5 \\
\hline Inclusão & 2 \\
\hline Social & 2 \\
\hline Médico & 1 \\
\hline
\end{tabular}

Observa-se que, das seis primeiras posiçôes relacionadas aos descritores, duas referem-se à educação, duas referem-se à saúde e duas apelam pelo direito ao atendimento. Em último lugar, o termo "médico" aparece apenas uma vez, o que pode indicar o desconhecimento de algumas pessoas relacionadas à importância do médico no APD.

Chama-nos atenção o fato do descritor "inclusão" ter sido mencionado apenas duas vezes. Sabemos que para haver inclusão, a escola tem que se modificar para incluir a pessoa com deficiência. Ela, a escola, precisa ser capaz de atender às necessidades de todos os alunos e não ao contrário! 
A Figura 1, a seguir, mostra a nuvem de tags dos descritores presentes nas pesquisas analisadas.

Figura 1: Tags dos descritores dos resumos das pesquisas

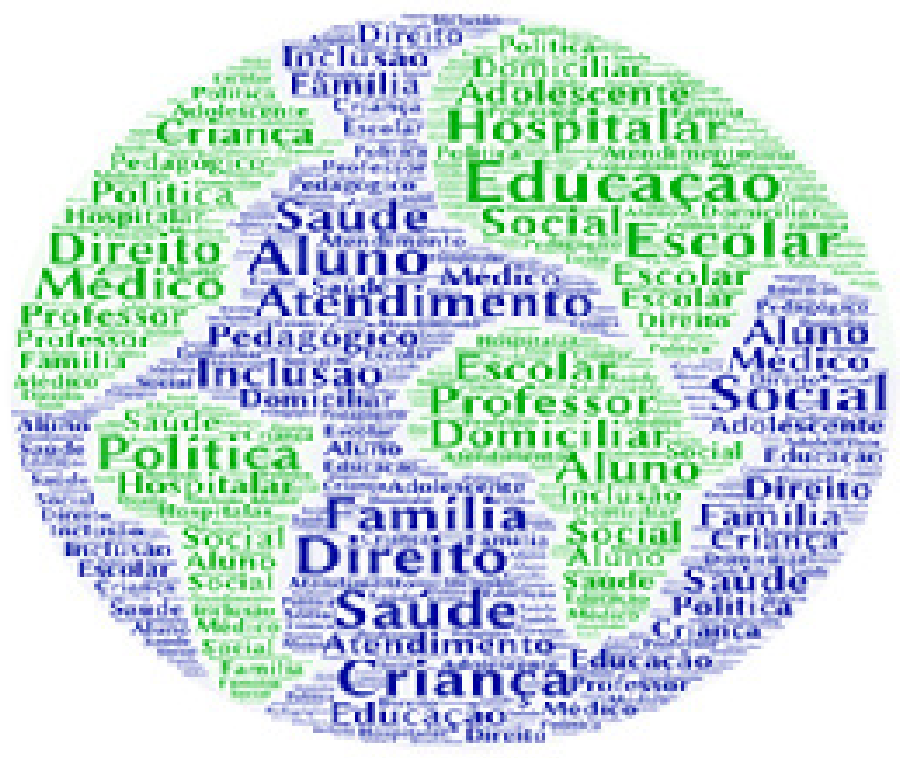

A leitura que se faz em relação à Tabela 2, cujos descritores "Escola", "Professor", "Educação", "Criança", "Aluno", "Hospitalar" e "Atendimento" ocupam destaque, mostra que os trabalhos de pesquisas focaram para a compreensão dos contextos relacionados às instituiçôes escola e hospital e seus atores sociais professor e aluno.

Seguido do descritor "Saúde", que participa do contexto do APD como consequência do trabalho desenvolvido pelos profissionais, médicos e professores, e as próprias condições biológicas e psicológicas do aluno, os outros descritores "Pedagógicos", "Família", "Social", "Direito" e "Política" aparecem com classificações próximas.

Assim, podemos pensar que esses descritores estão relacionados à efetivação do APD, pois a qualidade do atendimento pedagógico precisa da participação também da família, possibilitando uma melhor qualidade das interaçôes sociais. Os outros descritores têm uma incidência menor, mas não têm menor importância no APD e, por este motivo, também são focos das pesquisas. 
Tabela 2: Descritores dos textos das pesquisas

\begin{tabular}{|l|c|}
\hline \multicolumn{1}{|c|}{ Palavra } & Incidência \\
\hline Escola & 2694 \\
\hline Professor & 2139 \\
\hline Educação & 2086 \\
\hline Criança & 1780 \\
\hline Aluno & 1404 \\
\hline Hospitalar & 1365 \\
\hline Atendimento & 1077 \\
\hline Saúde & 878 \\
\hline Pedagógicos & 583 \\
\hline Família & 558 \\
\hline Social & 518 \\
\hline Direito & 402 \\
\hline Política & 316 \\
\hline Adolescente & 254 \\
\hline Médico & 184 \\
\hline Inclusão & 129 \\
\hline Domiciliar & 37 \\
\hline
\end{tabular}

A observação sobre as potencialidades do aluno é de suma importância para o contexto do APD, pois esta possibilita ao professor desenvolver seu trabalho focado não nas limitaçóes causadas pelo estado de saúde, mas trazendo ao aluno oportunidade de testar e demostrar suas capacidades, até mesmo como forma de entender a realidade que se apresenta possibilitando a estudante um contexto de inserção social.

O desenvolvimento cultural é a principal esfera em que é possível compensar a deficiência. Onde não é possível avançar no desenvolvimento orgânico, abre-se um caminho sem limites para o desenvolvimento cultural (VYGOTSKY,2011, p. 865).

Ao montarmos a nuvem de tags com os descritores presentes na Tabela 2, podemos ter uma figura como a seguinte. 
Figura 2: Tags dos descritores dos resumos das pesquisas

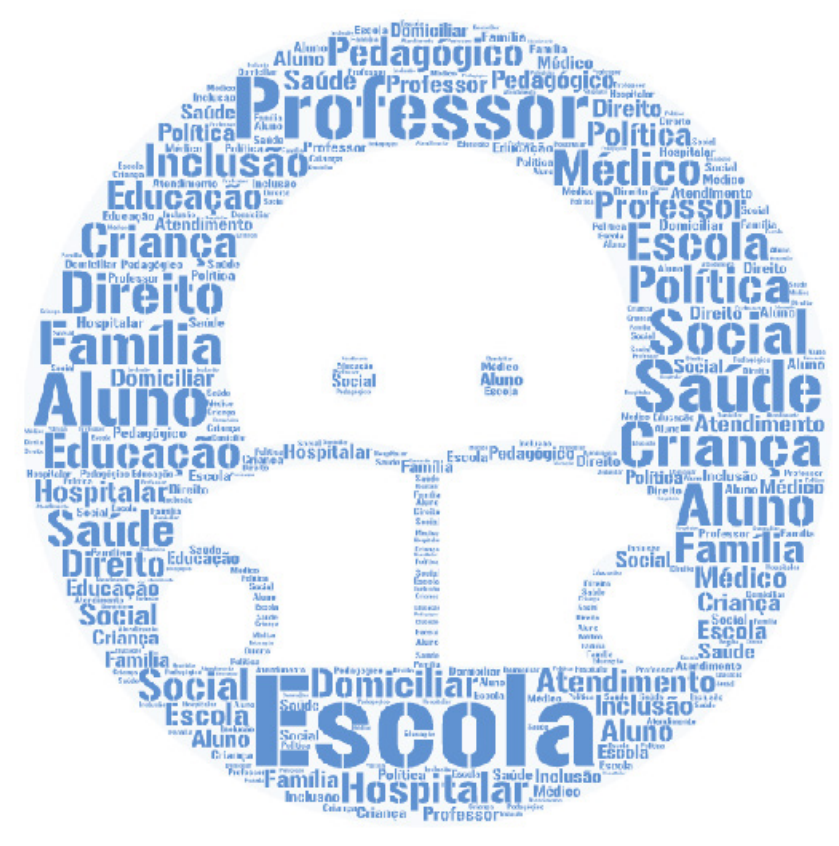

Estes resultados demostram que a pesquisa na área do APD não se limita apenas à escola ou ao hospital, ao aluno ou ao paciente, à equipe médica ou aos professores, mas a todos os contextos pertinentes à educação.

\section{Resultados da pesquisa no programa Harzing's Publish}

Os resultados obtidos no programa Harzing's Publish são condizentes a uma área ainda em crescimento, com pesquisadores novos e com poucas publicaçôes e citaçóes.

Segundo Gisbert e Panés (2009), o índice h, ou h-index, criado em 2005 pelo físico Jorge E. Hirsch, da University of California, é uma proposta para quantificar a produtividade e o impacto das investigaçóes de um determinado pesquisador, tendo como base os seus artigos mais citados. O índice h é calculado pela relação do número de trabalhos publicados e suas citaçóes. Por exemplo, um autor tem índice $\mathrm{h}=8$ se os seus oito artigos mais citados tiverem pelo menos oito citaçóes cada um.

Como podemos observar no Gráfico 5, o índice h de muitos trabalhos era inexistente ou zero, quando o maior foi dois. 
Gráfico 5: Fator $h$ das publicaçôes

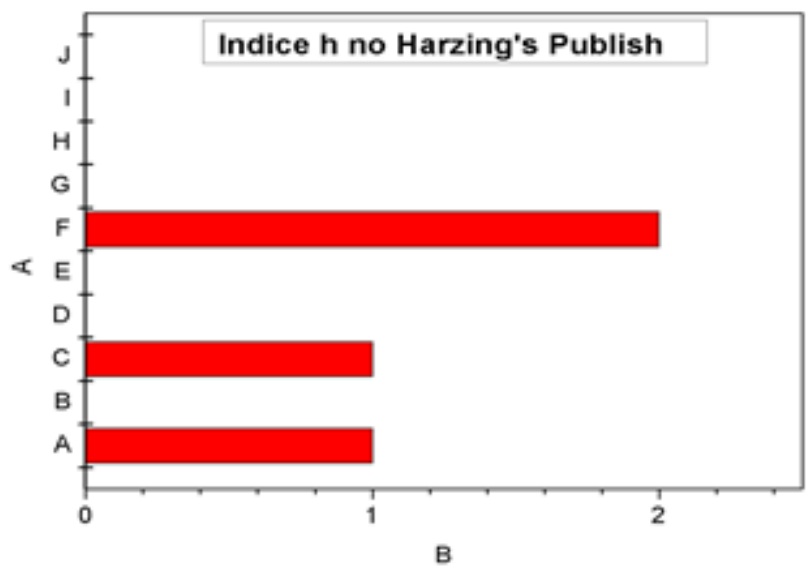

De acordo com o Gráfico 5, o índice h foi igual a $2(\mathrm{~h}=2)$. Ou seja, os dois artigos mais citados tiverem pelo menos duas citaçôes cada um.

Existe uma diferença na quantidade de citaçóes do programa Harzing's Publish e do Google Acadêmico, o que alteraria o resultado anterior. Esta disparidade pode ser explicada pela falta de registro do pesquisador. Podemos observar que os pesquisadores que têm o fator $h$, tem a mesma quantidade de citaçóes.

Por seu turno, de acordo com o Google Acadêmico, para o mesmo artigo houve, pelo menos, cinco citaçóes.

Gráfico 6: Citações no Google Acadêmico

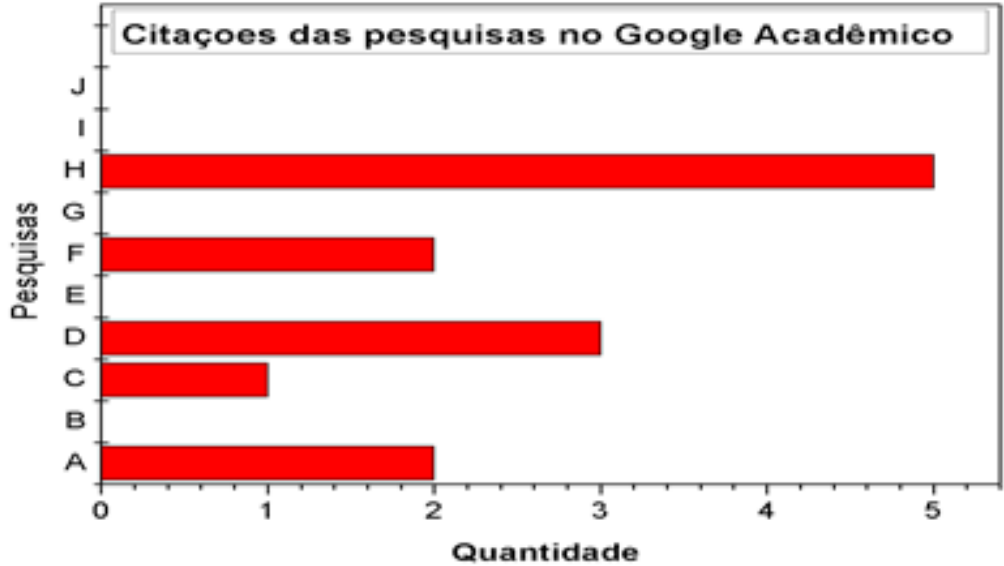


Se levarmos em conta as citaçôes no Google Acadêmico, podemos dizer que as publicaçōes tiveram maior repercussão entre os leitores (professores, familiares, profissionais da saúde...).

Pelos motivos óbvios constatados nesta pesquisa, pode-se dizer que os alunos que não podem frequentar a escola por motivo de doença não estão inseridos efetivamente na escola para todos. Portanto, não seria possível afirmar que o direito à educação e à inclusão escolar esteja garantido a eles.

Cumpre às classes hospitalares e ao atendimento pedagógico domiciliar elaborar estratégias e orientaçóes para possibilitar o acompanhamento pedagógico-educacional do processo de desenvolvimento e construção do conhecimento de crianças, jovens e adultos matriculados ou náo nos sistemas de ensino regular, no âmbito da educação básica e que encontram-se impossibilitados de frequentar escola, temporária ou permanentemente e, garantir a manutenção do vínculo com as escolas por meio de um currículo flexibilizado e/ou adaptado, favorecendo seu ingresso, retorno ou adequada integraçáo ao seu grupo escolar correspondente, como parte do direito de atenção integral (BRASIL, 2002, p. 13).

Se pensarmos na pesquisa científica de outras áreas, poderíamos dizer que temos uma pesquisa ainda pouco significativa nesta área, como demonstrado pelo índice h. Todavia, precisamos considerar que o primeiro trabalho que foi analisado nesta pesquisa data do ano de 2008. Podemos afirmar, então, que a pesquisa na área do APD está em crescimento. Para Thomaz, Assad e Moreira (2011) este índice demostra o crescimento de uma área de pesquisa, desde a publicação dos resultados das primeiras pesquisas.

Em uma crítica a este posicionamento simplista, Marques (2013) levanta outros pontos sobre o índice h, o item que mostra apenas a questáo da quantidade de publicações e citações e não leva em conta outros fatores da pesquisa, tais como: a área da pesquisa; que nas disciplinas das humanidades o contexto é diferente de outras áreas; a idade do pesquisador; o índice da própria revista que o artigo foi publicado e a publicação em livros.

Porém, para nossa pesquisa, o índice h se mostra relevante para demostrar a quantidade de pesquisas realizadas. No entanto, não podemos afirmar qual seria o impacto dessas investigaçôes. Por exemplo, para a CAPES, que usa o índice $h$ como parâmetro de avaliação, a pesquisa na área do APD náo teria tanta relevância. Por outro lado, se pensarmos nos professores, alunos e famílias que necessitam desta modalidade de ensino, ao terem acesso à pesquisa, à importância e ao impacto, podemos afirmar que o índice h é relevante e se mostra necessário para o aprimoramento das investigações realizadas.

\section{Considerações finais}

A realização desta investigação, assentada em bases de dados nacionais sobre o APD, nos anos de 2002 a 2015, englobou teses, dissertaçóes e TCC. Pode-se afirmar que possibilitou um conhecimento mais aprofundado em relação às pesquisas acadêmicas e suas contribuiçôes para a efetivação do APD. 
Usar a pesquisa como forma de entender e melhorar a escola e os processos de aprendizagens tem sido o trabalho de muitos pesquisadores, como Correia (1997; 2003; 2008a; b); Moreira (2014; 2016a; b); Moreira e Manrique (2012; 2014a; b; c); Vygotsky (1991; 1997; 2001; 2004; 2007; 2011); entre outros.

Tais pesquisadores têm mudado as formas de abordar e entender a construção do conhecimento e as implicaçóes sociais do atendimento ao aluno com necessidades educativas especiais. Mas para tal, precisaram responder suas questóes, seus problemas de pesquisas e as respostas surgiram porque usaram abordagens e técnicas de construção de dados efetiva e, principalmente, analisaram os dados embasados em um referencial teórico robusto.

Esta investigação nos possibilitou entender alguns aspectos que envolvem as pesquisas relacionadas ao APD, principalmente perceber que estamos no início da caminhada da efetivação do direito à escola para todos. Então, é imprescindível que existam mais pesquisas na área, assim como a divulgação das mesmas para a sociedade em geral, e, principalmente, para os professores, para que estes sejam pontes entre a academia e a sociedade, possibilitando mudanças no contexto escolar. Parafraseando Moreira e Manrique (2012), a escola inclusiva está em construção e a sua efetivação precisa de mudanças no cotidiano escolar.

Esta investigação nos fez refletir sobre o desafio da educação inclusiva e diversa. Embora nos faça enxergar que a inclusão é um enorme desafio a ser superado, seja na escola, seja na família, seja nos ambientes hospitalares, nos leva a acreditar que a legislação, um dia, será efetivamente cumprida.

Os resultados das análises das investigaçôes realizadas são contundentes: ainda há pouquíssima produção relacionada ao atendimento pedagógico domiciliar. Porém, há açóes sérias por parte de alguns pesquisadores e governos, que podem incentivar a implantação do APD em todo o País.

Nossas reflexốes representam, também, uma possibilidade de mudança, de recomeçar, especialmente se a atual realidade do ensino e aprendizagem dos alunos acamados se faz presente na vida de todos, pois é preciso que o professor, a família e o agente de saúde, sejam capazes de "reconhecer a interação social como patrimônio humano, que necessita ser lapidado, respeitando as conquistas efetivadas em cada etapa vencida, contribuindo para o sucesso das etapas que viráo" (MOREIRA; MANRIQUE, 2014c, p. 481, tradução nossa).

\section{Referências}

BRASIL. MINISTÉRIO DA EDUCAÇÃO. Lei de Diretrizes e Bases da Educaçáo Nacional, 1996. Disponível em: <http://www.planalto.gov.br/ccivil_03/leis/L9394.htm>. Acesso em: 7 ago. 2015.

BRASIL. Classe hospitalar e atendimento pedagógico domiciliar: estratégias e orientaçôes. Secretaria de Educação Especial. Brasília: MEC/SEESP, 2002.

BITTENCOURT, L. A. F.; PAUlA, A. de. Análise Cienciométrica de Produçâo Científica em Unidades de Conservação Federais do Brasil. Enciclopédia Biosfera, v. 8, n. 14, pp. 2044-2054, 2012.

BRIN, S.; PAGE, L. The anatomy of a large-scale hypertextual Web search engine. Computer Networks and ISDN Systems, Stanford, v.30, n.1, p.107-117, Apr.1998. 
CAPES. Portal de Periódicos da Capes. Disponível em: http://www.capes.gov.br/. Acesso em 4 dez. 2015.

CORREIA, L. M. Alunos com Necessidades Educativas Especiais nas Classes Regulares de Ensino. Porto: Porto Editora, 1997.

CORREIA, L. M. Educaçáo Especial e Inclusão: Quem disser que uma vive sem a outra não está no seu perfeito juízo. Porto: Porto Editora, 2003.

CORREIA, L. M. Inclusáo e Necessidades Educativas Especiais: Um guia para educadores e professores. Porto: Porto Editora, 2008a.

CORREIA, L. M. Dificuldades de aprendizagem específicas: Contributos para uma definição portuguesa. Porto: Porto Editora, 2008b.

DE PAULA, M. E. A. T.; ZAIAS, E.; SILVA, M. C. R. Políticas públicas em defesa do direito à educação: análise dos projetos de lei para expansão das classes hospitalares e atendimentos pedagógicos domiciliares no Brasil. Revista Educaçáo e Políticas em Debate, v. 4, n. 2, pp. 54-68, 2015.

ESTEVES, C. R. Pedagogia hospitalar: um breve histórico. 2008. Disponível em: <http://www.smec.salvador. ba.gov.br/site/documentos/espacovirtual/espaco-educacao-saude/classes-hospitalares>. Acesso em: 4 dez. 2015.

GISBERT, J. P.; PANÉS, J. Índice H de Hirsch: una nueva herramienta para medir la producción científica. Cirugía Espańola, Vol. 86, número 4, pp. 193-1955 2009.

GOOGLE ACADÊMICO. Sobre o Google Acadêmico. 2016. Disponível em: <http://scholar.google.com.br/ intl/pt-BR/scholar/about.html>. Acesso em: em 20 out. 2016.

LAPLANE, A. L. F.; JAJBHAY, S. F.; FREDERICO, J. C. C. Crianças com doença renal crônica não estudam? Revista Crítica Educativa, v. 1, n. 2447-4223, p. 218-229, 2015.

MARQUES, F. Os limites do Índice H. Pesquisa Fapesp, v. 207, p. 35-39, 2013.

MINAYO, M. C. S. Pesquisa social teoria método e criatividade. In: MINAYO, M. C. S. (Org.). Pesquisa Social: teoria, método e criatividade. 29 ed. Petrópolis, RJ: Vozes, 2009.

MOREIRA, G. E. Resolvendo problemas com alunos com Transtornos Globais do Desenvolvimento: desafios e conquistas. Educaçấo Matemática em Revista-RS, v. 01, n. 15, 2014. pp. 38-48.

MOREIRA, G. E. A Educaçāo Matemática Inclusiva no contexto da Pátria Educadora e do novo PNE: reflexốes no âmbito do GD7. Educaçáo Matemática em Pesquisa. São Paulo, v. 17, n. 3, 2016a. pp. 1-10.

MOREIRA, G. E. O ensino de Matemática para alunos surdos: dentro e fora do texto em contexto. Educaçáo Matemática em Pesquisa. Vol. 18, n. 2. São Paulo, 2016b. pp. 741-757.

MOREIRA, G. E.; MANRIQUE, A. L. O que pensam os professores que ensinam Matemática sobre a inclusão de alunos com NEE? Perspectivas sociológicas e educacionais em estudos da criança: as marcas das dialogicidades. Revista Luso-brasileira, 2012.

MOREIRA, G. E.; MANRIQUE, A. L. Educação inclusiva: representaçôes sociais de professores que ensinam matemática. In: TARTUCI, D. Educação Especial e Inclusão: das políticas públicas às práticas educativas. Poíesis Pedagógica, UFG, vol. 12, pp. 127-149, $2014 \mathrm{a}$.

MOREIRA, G. E.; MANRIQUE, A. L. Percepçôes dos professores acerca da inclusão de alunos com NEE em aulas de Matemática em Braga (Portugal) e no Distrito Federal (Brasil). Perspectivas da Educaçáo Matemática, v.7, n. 14, pp. 136-201. 2014b.

MOREIRA, G. E.; MANRIQUE, A. L. Challenges in Inclusive Mathematics Education: Representations by Professionals Who Teach Mathematics to Students with Disabilities. Creative Education, 5, 470-483, 2014c.

PETERS, I. O direito à educaçáo da criança em tratamento de saúde. Trabalho de Conclusâo de Curso. Curitiba: Universidade Federal do Paraná-UFPR, 2015.

SALLA, H.; SANTOS, P. F.; RAZUCK, R. C. de S. R. Atendimento Domiciliar: ações e reflexōes sobre a inclusão de um aluno com polineuropatia sensitivo motora. In: CAIXETA, J. E.; SOUSA, M. A.; SANTOS, P. F. (Ed.). Educação e Psicologia: mediaçōes possíveis em tempos de inclusão. Curitiba, PR: Editora CVR, 2015. p. 173-192.

SEVERINO, A. J. Metodologia do Trabalho Científico. 23 ed. São Paulo: Cortez, 2013.

THOMAZ, P. G.; ASSAD, R. S.; MOREIRA, L. F. P. Uso do Fator de impacto e do índice H para avaliar pesquisadores e publicaçōes. Arquivos Brasileiros de Cardiologia, v. 96, n. 2, p. 90-93, 2011. 
UNESCO. Declaraçáo Universal dos Direitos Humanos. 1948. Disponível em: <http://www.egov.ufsc.br/ portal/sites/default/files/anexos/25499-25501-1-PB.pdf>. Acesso em: 4 dez. 2015.

VANTI, N. A. P. Da bibliometria à webometria: uma exploração conceitual dos mecanismos utilizados para medir o registro da informação e a difusão do conhecimento. Ciência da Informação, v. 31, n. 2, p. 152-162, 2002.

VYGOTSKI, L. S. A formaçáo social da mente: o desenvolvimento dos processos psicológicos superiores. 4. ed. São Paulo: Martins Fontes, 1991.

VYGOTSKI, L. S. Obras Escogidas V. Fundamentos de defectologia. Madrid: Visor, 1997.

VYGOTSKI, L. S. Psicologia pedagógica. São Paulo: Martins Fontes, 2001.

VYGOTSKI, L. S. Teoria e método em Psicologia. São Paulo: Martins Fontes, 2004.

VYGOTSKI, L. S. La imaginación y el arte em la infancia. Madrid: Akal, 2007.

VYGOTSKI, L. S. A defectologia e o estudo do desenvolvimento e da educação da criança anormal. Revista Educaçáo e Pesquisa, v. 37, n. 4, p. 861-870, 2011.

XAVIER, L. Pedagogia hospitalar: que espaço é esse? 2013. Trabalho de Conclusão do Curso. Universidade Federal do Rio Grande do Sul-UFRS, Porto Alegre, 2013.

YAMAKAWA, E. K.; KUBOTA, F. I.; BEUREN, F. H.; SCALVENZI, L.; CAUCHICK-MIGUEL, P. A. Comparing the bibliographic management softwares: Mendeley, EndNote and Zotero. Revista Comunicaçáo, v. 26, n. 2, p. 167-176, 2014.

ZAIAS, E.; DE PAULA, E. M. A produçâo acadêmica sobre práticas pedagógicas em espaços hospitalares: análise de teses e dissertaçóes. Revista Educaçáo, Unisinos, v. 14, n. 3, p. 222-232, 2010. Disponível em: <http:// revistas.unisinos.br/index.php/educacao/article/view/701>. Acesso em: 20 out. 2016.

\section{Correspondência}

Geraldo Eustáquio Moreira - Universidade de Brasília, Campus Universitário Darcy Ribeiro, Faculdade de Educação - FE, Departamento de Métodos e Técnicas. CEP: 70.910-900. Asa Norte, Brasília, Distrito Federal, Brasil.

E-mail: geust2007@gmail.com - helmasalla@gmail.com

Recebido em 13 de abril de 2017

Aprovado em 01 de agosto de 2017 
